\title{
EFFECTS OF TWO 12-WEEK STRENGTHEENING PROGRAMMES ON FUNCTIONAL MOBLLITY, STRENGTH AND BALANCE OF OLDER ADULTS: COMPARISON BETWEEN TRX SUSPENSION TRAINING VERSUS AN ELASTIC BAND RESISTANCE TRAINING
}

\author{
Angus Gaedtke, ${ }^{1, A, B, C, D}$ Tobias Morat $2, \mathrm{~A}, \mathrm{D}, \mathrm{E}$ \\ 1 SPORTREIF Angus Gaedtke, Bochum, Germany \\ ${ }^{2}$ Institute of Movement and Sport Gerontology, German Sport University Cologne, Cologne, Germany

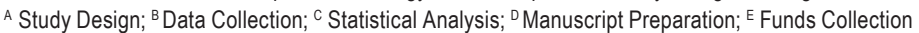 \\ Address for coprespondence: \\ Angus Gaedtke \\ Hammer Str. 63, 44866 Bochum, Germany \\ E-mail: gaedtke@sportreif.de
}

\begin{abstract}
Ahstract. No study has compared sling exercise training with elastic band resistance training in healthy older adults. Therefore, the purpose of this study was to determine whether different effects on functional mobility, strength and balance ability were produced by using different devices (sling trainer and elastic bands). Twenty-four participants were assigned to two different training groups, INT (TRX-OldAge) and CON (elastic bands). Participants trained three times per week for 30 minutes for 12 weeks. The Multisurface Obstacle Test for Older Adults (MSOT) and the 1-repetition maximum test using the chest press and the leg press were performed to assess functional mobility and dynamic strength, respectively. To examine balance ability, data of body-worn sensors and a force plate measured during different standing positions have been investigated. A main time effect occurred for functional mobility $(p=0.009)$ with a significant improvement within INT $(p=0.044)$, and for the chest press $(p=0.017)$ with a significant improvement within INT $(p=0.019)$. However, there was no group-by-time interaction in any of the measured parameters. Compared to elastic band resistance training, TRX-OldAge induced similar effects on the functional mobility, strength and balance ability of healthy older adults.
\end{abstract}

Key WOPlls: sling exercise training, TRX suspension training, healthy older adults, intervention, core stability

\section{Introduction}

The aging process leads to a reduction in the number of motor units and the number and size of muscle fibres, frequently resulting in a loss of strength, balance and mobility (Vandervoort, 2002). However, several previous studies demonstrated positive effects of resistance training on these important resources of older adults (Barnett, Smith, Lord, Williams, Baumand, 2003; Clemson et al., 2012; Irez, Ozdemir, Evin, Irez, Korkusuz, 2011; Kaesler, Mellifont, Kelly, Taaffe, 2007; Krebs, Scarborough, McGibbon, 2007; Taylor et al., 2012). For fall prevention in particular, 
guidelines recommend a combination of balance and resistance training (Sherrington, Tiedemann, Fairhall, Close, Lord, 2011). Following this approach, functional resistance training has gained increasing importance in recent years and shown an increase in the one repetition maximum and sit-to-stand power test performance and maximal walking speed (Henwood, Taaffe, 2006; Lohne-Seiler, Torstveit, Anderssen, 2013; Solberg et al., 2013).

An up-and-coming form of functional resistance training that improves functional mobility, strength and balance ability is sling exercise training. For younger adults, upper-body strength improvements (1 - repetition maximum [1 RM] test at chest press), ranging from 4\% to 11\%, were shown (Dannelly et al., 2011; Maté-Muñoz, Monroy, Jodra Jiménez, Garnacho-Castaño, 2014; Prokopy et al., 2008). Furthermore, leg strength (1 RM at leg press or back squat at a Smith machine) increased between 13\% and 66\% (Dannelly et al., 2011; Maté-Muñoz et al., 2014). With regard to balance ability, single-leg stance of young female softball players significantly increased by about $57 \%$ and 65\% (Prokopy et al., 2008). In a study by Stray-Pedersen, Magnussen, Kuffel, Seiler, Katch (2006), single-leg stance on the non-dominant leg improved significantly by about $45 \%$. On the other hand, the observed single-leg stance improvements of the dominant leg of elite soccer players of $18 \%$ were not significant (Stray-Pedersen et al., 2006). Younger low back pain patients enhanced static (normal stance) and dynamic (normal stance after an $180^{\circ}$ rotation) balance by about $23 \%$ and $50 \%$ (measured as sway speed of the centre of pressure), respectively (Kim, Kim, Bae, Kim, 2013). In another study, patients with hemiplegia achieved a comparable improvement of $30 \%$ for the normal stance sway length of the centre of pressure after eight weeks of sling training (Park, Hwangbo, 2014) However, data have only been collected using younger subjects and patients. Studies targeting older adults have been predominantly conducted with older patients (Bae, Jung, Lee, Cho, 2014; Lee, Lee, 2014; Schroeder, Knauerhase, Kundt, Schober, 2012; Schroeder, Knauerhase, Kundt, Schober, 2014; Tsauo, Cheng, Yang, 2008), rather than healthy older adults. For older adults with total knee replacement, a six-week sling training led to significant quadriceps and hamstring strength improvements of $77 \%$ and $56 \%$, respectively (Bae et al., 2014). Furthermore, functional mobility (Timed Up and Go test [TUG]) improved significantly by about $5 \%$ after four weeks of sling training for older hemiplegic patients (Lee, Lee, 2014). Older osteoporosis patients significantly enhanced TUG performance by around 25\% after three-months of sling training (Schroeder et al., 2014).

However, because of different target groups, study designs and measures, results are not consistent. Beyond that, there is still a lack of knowledge about the effects of sling training in healthy older adults. Based on these constraints in literature, a new specific sling exercise training programme for a target group of healthy older adults was developed (TRX-OldAge by Gaedtke, Morat, 2015). Based on this, the purpose of this study was to analyse and compare the effects of TRX-OldAge and Thera-Band training on strength, functional mobility and balance ability of older adults. We hypothesized that a 12-week resistance training with three sessions per week induced significant greater functional mobility, strength and balance ability improvements for TRX-OldAge than occurred for elastic band resistance training.

\section{Material and Methods}

\section{Study design}

The present pilot study is based on a 12-week, single-blinded, randomized controlled trial with two training groups in a parallel design. An initial assessment (T1) was conducted prior to intervention and was repeated immediately after the training intervention (T2). In order to ensure a gender balance between the two treatment groups, a block randomization with a block size of $3 \times 2$ was separately made for men and women. The ethics 
committee at the German Sport University Cologne granted ethical approval. The study design took into account the principles set out in the Declaration of Helsinki (2008). All participants completed consent forms. Participants were informed that all the data collected would be processed anonymously. The study was conducted in the City of Cologne, Germany.

\section{Participants}

The participants were community-dwelling healthy older adults aged 60 years and older. They had been recruited by advertisements placed on web pages, in local newspapers, posters, and flyers in Cologne and the surrounding area. Participants had to bring in a medical certificate from his or her physician to declare their good state of health. Exclusion criteria for participating in this study were hypertension not being regulated by a physician, acute and chronic heart diseases, herniated disc in the last six months, acute inflammation of the musculoskeletal system, post-polio syndrome, and osteoporosis.

\section{Intervention}

Participants were randomly assigned into the two different training groups. One group received the TRXOldAge program (INT, see Gaedtke, Morat, 2015). The control group (CON) conducted an elastic band resistance training, which has also been shown to have positive effects on upper-body strength (Fahlman, McNevin, Boardley, Morgan, Topp, 2011), lower-body strength (Fahlman et al. 2011; Krebs et al., 2007; O'Shea, Taylor, Paratz, 2007), balance (measured as area of centre of gravity movement during normal stance), sit-to-stand performance (Choi, Kim, Hwang, 2011), Timed Up and Go Test time (Ribeiro, Teixeira, Brochado, Oliveira, 2009), gait velocity and step length of older adults (Fahlman et al., 2011). Beyond that, compared to sling training, with elastic bands we could generate similar exercises. The exercise programme for TRX-OldAge was published in a previous study (Gaedtke, Morat, 2015). For CON, seven exercises that train similar muscle groups as in TRX-OldAge were implemented.

Both groups (INT and CON) trained outdoors for 12 weeks (three times per week for 30 minutes) from June to August. An installed pavilion protected participants from rain and sun. The participants trained in pairs. For INT, two TRX Suspension Trainers (TRX; Fitness Anywhere LLC, San Francisco, California, USA) were attached to a TRX Suspension Frame (TRX; Fitness Anywhere LLC, San Francisco, California, USA), while CON trained with Thera-Bands of different thickness for variation in resistance (resistance at $100 \%$ extension: yellow $=1.3 \mathrm{~kg}$, red $=1.8 \mathrm{~kg}$, green $=2.3 \mathrm{~kg}$, blue $=3.2 \mathrm{~kg}$, black $=4.4 \mathrm{~kg}$, silver $=6.0 \mathrm{~kg}$, gold $=9.8 \mathrm{~kg}$ ).
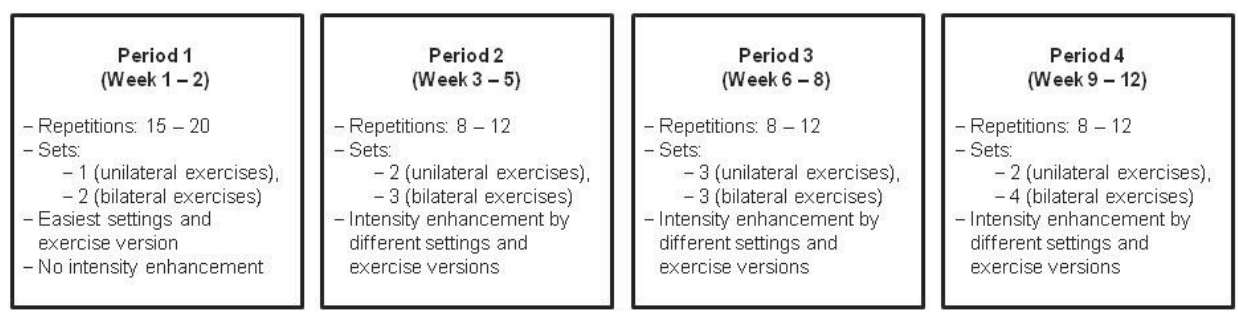

Figure 1. Training periods for both groups 
Training was separated into four periods (see Figure 1) with different configurations of training control. A professional instructor supervised every training session. At the beginning of each session, a brief warm-up phase, which consisted of walking and mobility exercises (knee lift, heel-to-toe walk, shoulder rotation etc.), was implemented. In a cool-down phase at the end of a session participants executed stretching exercises. Subsequently to the warm-up phase, participants of INT followed the original prescription and order of the TRX-OldAge programme (Gaedtke, Morat, 2015). Between each set, they had a rest of 90 seconds. The intensity and number of repetitions were enhanced as soon as the participant reached two more repetitions in the last set of an exercise in two consecutive training sessions. Firstly, the number of repetitions was increased from eight to ten and from ten to twelve. After completing twelve repetitions, training intensity was raised. The progress in intensity was implemented by different exercise versions and settings (Gaedtke, Morat, 2015).

For CON, the load was defined by band colours and their depending resistance. Version A of an exercise means to train with the yellow and red elastic bands, version $B$ was based on the green and blue bands, while version $\mathrm{C}$ included the black, silver and gold bands. Further settings for CON were realized as follows: band position on extremities or band folding (single-layer, twofold). During training, the participants were asked to rate their individual exertion after each set of an exercise on the OMNI-RES scale (Robertson et al., 2003). Exertion values of six to eight were classified as optimal. If the exertion was lower than the optimal range, intensity was increased in the next session.

\section{Outcomes}

The primary outcomes were the functional mobility, dynamic maximum lower-body strength, upper-body strength (1 RM) and balance ability. Physical activity and body weight were secondary outcomes.

Following a five-minute warm-up period of ergometer cycling with 1 watt per kg body weight, two researchers carried out the assessment.

Functional mobility was assessed using the Multisurface Obstacle Test (MSOT; Morat, Kroeger, Mechling, 2013). Within the MSOT, participants have to walk an 8-metre track with different obstacles and uneven surfaces. After three familiarization trials without the MSOT, participants had to complete three trials with their habitual gait speed (Morat et al., 2013). The best walking time (sec.) of these three trials on the MSOT was analysed.

One repetition maximum (1 RM) for the upper body and lower body was assessed by using the Ergo-Fit Chest Press 4000 and the Ergo-Fit Leg Press 4000 (Pirmasens, Germany), respectively. Both devices were adjusted for each participant. An 80-degree knee angle was defined as the initial position for the leg press. For the chest press, a 60-degree angle between trunk and abducted upper arm was used. After a familiarization set to the lowest possible intensity (lightest weight), 10-15 repetitions, and a following one-minute rest period, the researcher started the 1 RM testing procedure. In the first set, a load for three to five repetitions to fatigue was used. Subsequent to this, a two-minute rest period was conducted. For a maximum of four additional sets, a near-maximum load was estimated until 1 RM was achieved. If a single repetition failed, the load was reduced by $2.5 \%$ to $5 \%$ for the chest press and by $5 \%$ to $10 \%$ for the leg press. On the other hand, intensity was increased if the participant performed more than one repetition correctly (Spring, Franklin, de Jong, 2010). During the two-minute rest period between the sets, participants rated their individual exertion on the OMNI-RES scale (Robertson et al. 2003). If the 1 RM was not reached until the final set (after 1 familiarization set, 1 set of maximum 3-5 repetitions and a maximum of 
4 additional sets of maximum 2-3 repetitions), participants should perform as many repetitions as possible. Based on this number of repetitions, the hypothetical 1 RM was estimated (Giessing, 2003). Both 1 RM upper-body and lower-body strength were measured in kilograms $(\mathrm{kg})$.

Balance ability was measured on a Kistler force plate (type 9287B, Winterthur, Switzerland) with a frequency of $200 \mathrm{~Hz}$ with BioWare Software (version 4.0.x, type 2812A) and six APDM sensors (Portland, Oregon, USA). The six APDM movement sensors were attached to the followings positions: instep (left and right foot), tibia right above the ankles (left and right foot), lumbar spine and sternum (see Figure 2).

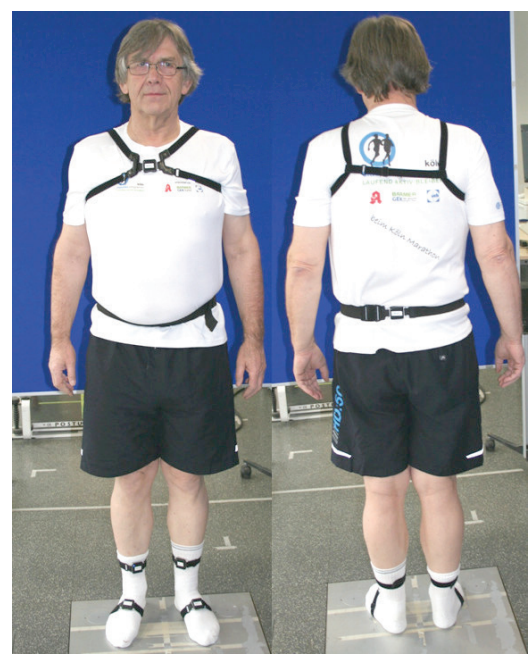

Figule 2. Movement sensor positions for balance ability measurement

Participants were instructed to stand as still as possible in the following standing positions on the force plate without (X) and with (A), an Airex Balance Pad: 1) closed-leg stance (CS); 2) tandem stance with the left foot forward (TS); 3) tandem stance with the right foot forward (TS); 4) single-leg stance on the dominant leg (SS_do); 5) singleleg stance on the not dominant leg (SS_ndo). One shoeless trial for each stance was executed with a maximum duration of 30 seconds (see Figure 3). If the maximum duration was reached or the participant lost their balance, time and data recording was stopped by the researcher. Analysis included root mean square (RMS) values of the lumbar spine sensor acceleration (ACC, measured in $\mathrm{m} / \mathrm{s}^{2}$ ) for medio-lateral (ML) and anterior-posterior (AP) direction, RMS values of the force plate force (FOR, measured in N) for ML and AP direction and centre of pressure (COP) velocity (COP_TRA, measured in $\mathrm{mm} / \mathrm{s}$ ). In respect of the tandem stance with the left and right foot forward, both standing positions were summarized together by generating a mean. Beyond that, the single-leg stance was discriminated between standing on the dominant (do) and not dominant leg (ndo). For balance ability, values were revised from analysis if the participant was not able to stand for at least ten seconds. 


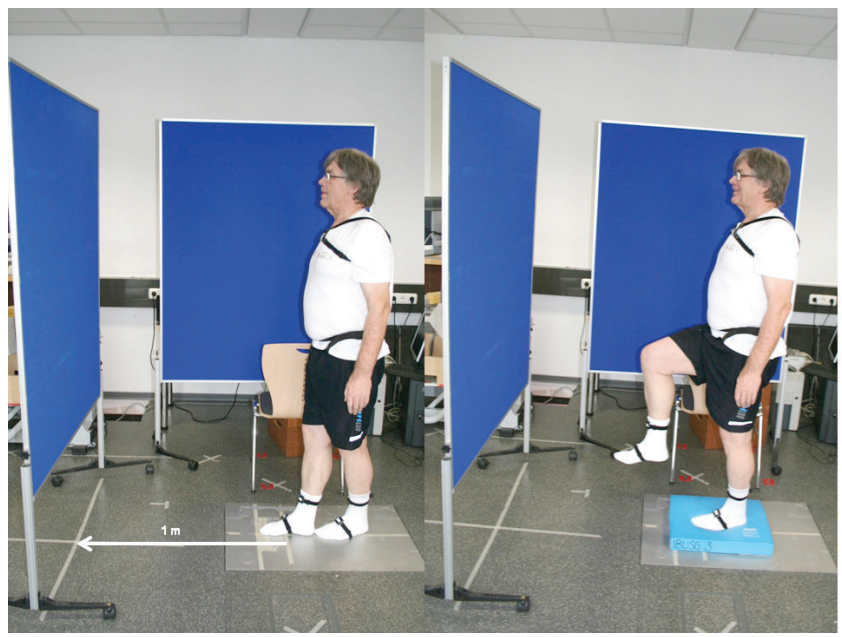

Figure 3. Exemplary standing positions during balance ability measurement

Physical activity was measured with the German-Physical Activity Questionnaire-50+ (German-PAQ-50+, Huy, Schneider, 2008). Its items investigate the time per week spent on different activities. By summing up the five categories (housework, gardening, leisure time, sports and profession) and multiplying the time spent with metabolic rate values (Ainsworth et al., 2000) a total energy consumption per week can be generated (measured in $\mathrm{kcal}$ per week). A further secondary outcome was body weight (measured in $\mathrm{kg}$ ).

\section{Statistical methods}

Statistical analysis was conducted using IBM SPSS Statistics for Windows (version 22, IBM, Armonk, New York, USA). The level of significance was set at $\alpha=.05$. Boxplots of the different $\Delta$-variables (T2-T1) indicated extreme outliers. If they were three times as large as the interquartile range, they were excluded from further analysis. A two-way repeated measures ANOVA (with the factors group and time) was executed. The Bonferroni post hoc test located specific differences afterwards. In the case of the preconditions of ANOVA not being fulfilled, the Friedman test or Kruskal-Wallis test were used instead.

G*Power software 3.1 (Faul, Erdfelder, Lang, Buchner, 2007) was used to calculate effect sizes and power for each test. For this, effect size was determined with partial $\eta^{2}$ values of the two-way repeated measures ANOVA for the relevant tests.

\section{Results}

A total of 22 healthy older adults, 17 males and 5 females completed the study (see Figure 4). The following diseases were present: hypertension adjusted by a physician $(n=11)$, type 2 diabetes $(n=4)$, rheumatoid arthritis $(n=1)$, scoliosis $(n=2)$, herniated disc more than 10 years ago $(n=3)$, elevated blood cholesterol level $(n=1)$, Bechterew's disease $(n=1)$, asthma $(n=1)$, tetraparesis $(n=1)$. Total training compliance was $81 \pm 11 \%$ with 85 
$\pm 10 \%$ for INT and $77 \pm 11 \%$ for CON. Baseline data is shown in Table 1. There were no significant group differences at $\mathrm{T} 1$.

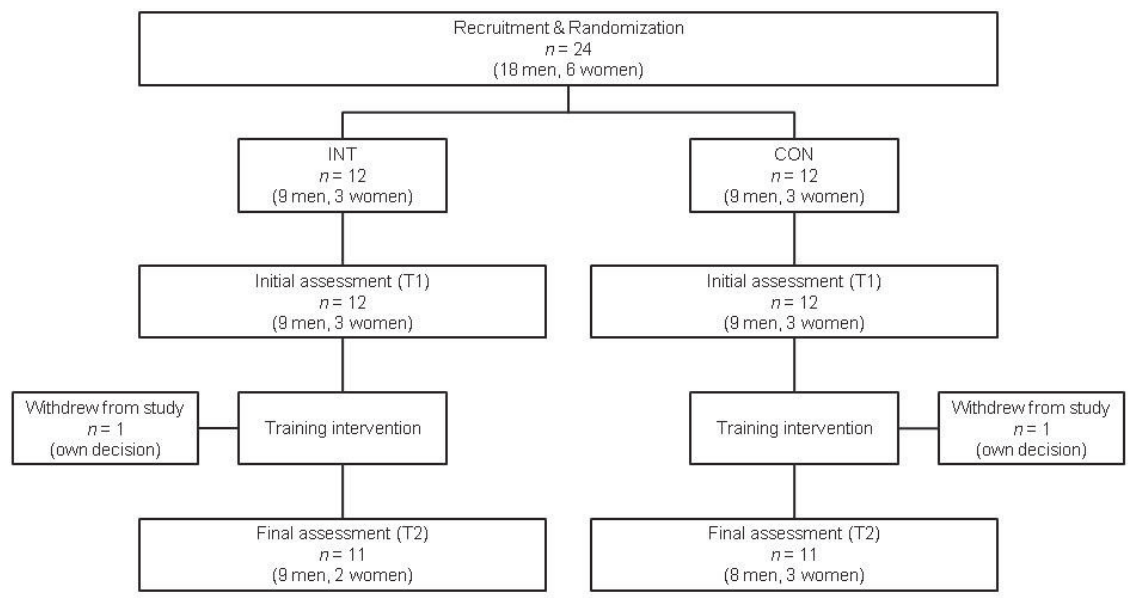

Figule 4. Process chart

Table 1. Baseline anthropometric data

\begin{tabular}{|c|c|c|c|c|c|c|}
\hline & \multirow{2}{*}{\multicolumn{2}{|c|}{ INT }} & \multirow{2}{*}{\multicolumn{2}{|c|}{ CON }} & \multirow{2}{*}{\multicolumn{2}{|c|}{ Total }} \\
\hline & & & & & & \\
\hline & \multicolumn{2}{|c|}{$\mathrm{n}=11$} & \multicolumn{2}{|c|}{$\mathrm{n}=11$} & \multicolumn{2}{|c|}{$n=22$} \\
\hline & $\mathrm{M} \pm \mathrm{SD}$ & $95 \% \mathrm{Cl}$ & $\mathrm{M} \pm \mathrm{SD}$ & $95 \% \mathrm{Cl}$ & $\mathrm{M} \pm \mathrm{SD}$ & $95 \% \mathrm{Cl}$ \\
\hline Age (in years) & $66.3 \pm 4.2$ & 63.4 to 69.1 & $67.3 \pm 4.2$ & 64.5 to 70.1 & $66.8 \pm 4.1$ & 64.9 to 68.6 \\
\hline Height (in m) & $1.76 \pm 0.08$ & 1.70 to 1.81 & $1.69 \pm 0.11$ & 1.61 to 1.76 & $1.72 \pm 0.10$ & 1.68 to 1.77 \\
\hline Body weight (in kg) & $88.4 \pm 16.3$ & 77.4 to 99.4 & $88.6 \pm 21.1$ & 74.4 to 102.8 & $88.5 \pm 18.4$ & 80.3 to 96.7 \\
\hline
\end{tabular}

INT = intervention group (TRX-OldAge); CON = control group (elastic band resistance training); $\mathrm{n}=$ sample size; $\mathrm{M}=$ mean; $\mathrm{SD}=$ standard deviation; $\mathrm{Cl}=$ confidence interval.

Body weight analysis revealed no group-by-time interaction $\left(F(1,20)=0.002, p=0.969, \eta_{\text {par }}^{2}<0.001\right)$. No main time $\left(F(1,20)=1.316, p=0.265, \eta_{\text {par }}^{2}=0.062\right)$ or group effects $\left(F(1,20)=0.001, p=0.981, \eta_{\text {par }}^{2}<0.001\right)$ exist.

For physical activity, no group-by-time interaction $\left(F(1,18)=0.035, p=0.854, \eta_{\text {par }}^{2}=0.002\right)$, main time $\left(F(1,18)=0.669, p=0.424, \eta_{\text {par }}^{2}=0.036\right)$ or group effects $\left(F(1,18)=0.578, p=0.457, \eta_{\text {par }}^{2}=0.031\right)$ are present.

The analysis of functional mobility showed no group-by-time interaction $(F(1,19)=0.007, p=0.936$, $\left.\eta_{\text {par }}^{2}<0.001\right)$. The main time effect $\left(F(1,19)=8.361, p=0.009, \eta^{2}\right.$ par $\left.=0.306\right)$ was significant and post hoc analysis revealed a significant MSOT time reduction between T1 and T2 of about $5 \%$ for INT ( $p=0.044)$, but not for CON $(p=0.067)$. The main group effect $\left(F(1,19)=0.052, p=0.821, \eta^{2}\right.$ par $\left.=0.003\right)$ was not significant.

For leg strength, no significant group-by-time interaction $\left(F(1,18)=0.125, p=0.728, \eta^{2}\right.$ par $\left.=0.007\right)$, main effect for time $\left(F(1,18)=0.422, p=0.524, \eta_{\text {par }}^{2}=0.023\right)$ or group $\left(F(1,18)=3.208, p=0.090, \eta_{\text {par }}^{2}=0.151\right)$ are present.

In respect of $1 \mathrm{RM}$ upper-body strength, analysis showed no significant group-by-time interaction $\left(F(1,18)=0.709, p=0.411, \eta_{\text {par }}^{2}=0.038\right)$. The main time effect $\left(F(1,18)=6.914, p=0.017, \eta_{p a r}^{2}=0.278\right)$ reached 
statistical significance. Post hoc analysis revealed a significant improvement of upper-body strength within INT of about $9 \%(p=0.019)$, whereas the $5 \%$ improvement of CON did not reach statistical significance $(p=0.244)$. The main group effect $\left(F(1,18)=0.352, p=0.560, \eta^{2}\right.$ par $\left.=0.019\right)$ was not significant (see Table 2$)$.

Table 2. Changes of physical activity, 1-repetition maximum and Multisurface Obstacle Test for Older Adults results between T1 and T2

\begin{tabular}{|c|c|c|c|c|c|c|c|}
\hline Variable & Group & $\mathrm{n}$ & $\begin{array}{c}\mathrm{T} 1 \\
\mathrm{M} \pm \mathrm{SD}\end{array}$ & $\begin{array}{c}\mathrm{T} 2 \\
\mathrm{M} \pm \mathrm{SD}\end{array}$ & $\begin{array}{l}\text { Mean change } \\
(95 \% \mathrm{Cl})\end{array}$ & Effect size & Power \\
\hline \multirow{2}{*}{ Physical activity (1000 kcal/week) } & INT & 9 & $13.3 \pm 8.1$ & $14.8 \pm 11.4$ & $1.5(-3.2$ to 6.1$)$ & 0.04 & 0.67 \\
\hline & CON & 11 & $17.3 \pm 14.1$ & $19.7 \pm 18.9$ & $2.3(-6.3$ to 11.0$)$ & & \\
\hline \multirow{2}{*}{ Leg press $(\mathrm{kg})$} & INT & 9 & $171.2 \pm 65.0$ & $165.7 \pm 57.6$ & $-5.6(-42.0$ to 30.8$)$ & 0.08 & 0.11 \\
\hline & CON & 11 & $241.6 \pm 112.3$ & $222.8 \pm 101.1$ & $-18.8(-88.5$ to 50.9$)$ & & \\
\hline \multirow{2}{*}{ Chest press (kg) } & INT & 11 & $59.1 \pm 16.9$ & $64.6 \pm 15.4^{*}$ & $5.5(-0.4$ to 11.4$)$ & 0.20 & 0.39 \\
\hline & CON & 9 & $55.8 \pm 19.4$ & $58.6 \pm 20.2$ & $2.8(-0.1$ to 5.7$)$ & & \\
\hline \multirow{2}{*}{ MSOT (s) } & INT & 11 & $7.65 \pm 2.08$ & $7.24 \pm 2.33^{*}$ & $-0.41(-0.84$ to 0.23$)$ & 0.03 & 0.06 \\
\hline & CON & 10 & $7.81 \pm 1.03$ & $7.43 \pm 1.26$ & $-0.39(-0.82$ to 0.05$)$ & & \\
\hline
\end{tabular}

INT = intervention group (TRX-OldAge); $\mathrm{CON}=$ control group (elastic band resistance training); $\mathrm{n}=$ sample size; $\mathrm{M}=$ mean; $\mathrm{SD}=$ standard deviation; $\mathrm{Cl}=$ confidence interval; MSOT = Multisurface Obstacle Test for Older Adults; ${ }^{*} p<0.05$ significant difference in comparison to T1.

For CSX_RMS_ACC_AP, no significant time effect is present $\left(X^{2}(1)=0.727, p=0.523, w=0.182\right)$. At T1 a significant group difference exists $\left(X^{2}(1)=4.554, p=0.033, w=0.455\right)$ that could not be found at T2 $\left(X^{2}(1)=0.475, p=0.491, w=0.147\right)$. Analysis of CSX_RMS_FOR_AP showed no significant group-by-time interaction $\left(F(1,18)=1.240, p=0.280, \eta^{2}\right.$ par $\left.=0.064\right)$. The main time effect $\left(F(1,18)=17.914, p=0.001, \eta_{p a r}^{2}=0.499\right)$ reached statistical significance. Post hoc analysis revealed a significant improvement within INT $(p=0.032)$ of $11 \%$ and within CON $(p=0.002)$ of $20 \%$. The main group effect was not significant $(F(1,18)=0.631, p=0.437$, $\left.\eta_{p a r}^{2}=0.034\right)$. In respect of TSX_RMS_FOR_AP, neither group-by-time interaction $(F(1,13)=0.249, p=0.626$, $\left.\eta_{\text {par }}^{2}=0.019\right)$ nor main group effect $\left(F(1,13)=0.121, p=0.734, \eta_{\text {par }}^{2}=0.009\right)$ are significant. Only the main time effect $\left(F(1,13)=7.367, p=0.018, \eta_{p a r}^{2}=0.362\right)$ reached statistical significance. Post hoc analysis only yielded a significant improvement within INT $(p=0.035)$ of $17 \%$. None of the remaining balance variables without the Airex Balance Pad demonstrated any significant group-by-time interactions, main time and group effects (see Appendix I and Table 3).

With the exception of TSA_RMS_ACC_ML, no balance variables on the Airex Balance Pad showed any significant group-by-time interactions; main time effect and main group effect (see Appendix II). TSA_RMS_ACC_ $M L$ analysis revealed no significant group-by-time interaction $\left(F(1,7)=0.117, p=0.743, \eta_{p a r}^{2}=0.016\right)$ and no main time effect $\left(F(1,7)=0.555, p=0.481, \eta^{2}\right.$ par $\left.=0.073\right)$. Only group effect reached significance level $(F(1,7)=5.965$, $p=0.045, \eta_{\text {par }}^{2}=0.460$ ), but post hoc analysis demonstrated no group differences for T1 or T2 (see Table 4). 
Tahle 3. Changes of closed-leg stance, tandem stance and single-leg stance between T1 and T2

\begin{tabular}{|c|c|c|c|c|c|c|c|c|}
\hline & Variable & Group & $\mathrm{n}$ & $\begin{array}{c}\mathrm{T} 1 \\
\mathrm{M} \pm \mathrm{SD}\end{array}$ & $\begin{array}{c}\mathrm{T} 2 \\
\mathrm{M} \pm \mathrm{SD}\end{array}$ & $\begin{array}{c}\text { Mean change } \\
(95 \% \mathrm{Cl})\end{array}$ & Effect size & Power \\
\hline \multirow{10}{*}{ త্ } & \multirow{2}{*}{ RMS_ACC_ML $\left(\mathrm{m} / \mathrm{s}^{2}\right)$} & INT & 11 & $0.09 \pm 0.04$ & $0.14 \pm 0.09$ & 0.05 (0.01 to 0.08$)$ & \multirow{2}{*}{0.52} & \multirow{2}{*}{0.87} \\
\hline & & CON & 11 & $0.18 \pm 0.13$ & $0.13 \pm 0.10$ & $-0.05(-0.12$ to 0.02$)$ & & \\
\hline & \multirow{2}{*}{ RMS_ACC_AP $\left(\mathrm{m} / \mathrm{s}^{2}\right)$} & INT & 11 & $0.06 \pm 0.02$ & $0.11 \pm 0.08$ & $0.05(-0.01$ to 0.11$)$ & \multirow{2}{*}{0.43} & \multirow{2}{*}{0.69} \\
\hline & & CON & 11 & $0.10 \pm 0.05$ & $0.13 \pm 0.07$ & $0.03(-0.02$ to 0.08$)$ & & \\
\hline & \multirow{2}{*}{ RMS_FOR_ML (N) } & INT & 11 & $6.44 \pm 1.66$ & $6.40 \pm 1.12$ & $-0.03(-0.62$ to 0.55$)$ & \multirow{2}{*}{0.25} & \multirow{2}{*}{0.56} \\
\hline & & CON & 10 & $6.79 \pm 1.72$ & $7.16 \pm 1.66$ & $0.37(-0.22$ to 0.97$)$ & & \\
\hline & \multirow{2}{*}{ RMS_FOR_AP (N) } & INT & 11 & $3.41 \pm 1.25$ & $3.05 \pm 0.97^{*}$ & $-0.36(-0.78$ to 0.06$)$ & \multirow{2}{*}{0.14} & \multirow{2}{*}{0.22} \\
\hline & & CON & 9 & $3.17 \pm 1.07$ & $2.54 \pm 1.01^{*}$ & $-0.62(-0.89$ to -0.36$)$ & & \\
\hline & \multirow{2}{*}{ COP_TRA $(\mathrm{mm} / \mathrm{s})$} & INT & 11 & $10.1 \pm 2.79$ & $11.1 \pm 3.50$ & $1.00(-0,70$ to 2.70$)$ & \multirow{2}{*}{0.33} & \multirow{2}{*}{0.83} \\
\hline & & CON & 10 & $12.0 \pm 3.18$ & $11.7 \pm 3.04$ & $-0.3(-1.30$ to 0.70$)$ & & \\
\hline \multirow{10}{*}{ 㸴 } & \multirow{2}{*}{$\begin{array}{l}\text { RMS_ACC_ML } \\
\left(\mathrm{m} / \mathrm{s}^{2}\right)\end{array}$} & INT & 8 & $0.15 \pm 0.08$ & $0.14 \pm 0.05$ & $-0.01(-0.08$ to 0.05$)$ & \multirow{2}{*}{0.10} & \multirow{2}{*}{0.11} \\
\hline & & CON & 7 & $0.15 \pm 0.09$ & $0.13 \pm 0.05$ & $-0.03(-0.11$ to 0.05$)$ & & \\
\hline & \multirow{2}{*}{ RMS_ACC_AP $\left(\mathrm{m} / \mathrm{s}^{2}\right)$} & INT & 8 & $0.17 \pm 0.08$ & $0.15 \pm 0.06$ & $-0.02(-0.07$ to 0.03$)$ & \multirow{2}{*}{0.11} & \multirow{2}{*}{0.13} \\
\hline & & $\mathrm{CON}$ & 7 & $0.16 \pm 0.06$ & $0.15 \pm 0.05$ & $-0.01(-0.04$ to 0.03$)$ & & \\
\hline & \multirow{2}{*}{ RMS_FOR_ML (N) } & INT & 8 & $6.98 \pm 1.49$ & $7.14 \pm 1.34$ & $0.16(-0.33$ to 0.66$)$ & & \\
\hline & & CON & 7 & $6.89 \pm 1.02$ & $7.03 \pm 0.79$ & $0.14(-0.33$ to 0.61$)$ & 0.03 & 0.06 \\
\hline & & INT & 8 & $4.71 \pm 1.26$ & $3.90 \pm 1.04^{*}$ & -0.81 (-1.89 to 0.28$)$ & & \\
\hline & RMS_FOR_AP (N) & $\mathrm{CON}$ & 7 & $4.42 \pm 0.82$ & $3.87 \pm 0.72$ & $-0.56(-0.82$ to -0.29$)$ & 0.14 & 0.17 \\
\hline & & INT & 8 & $27.34 \pm 9.30$ & $26.16 \pm 8.82$ & $-1.16(-5.37$ to 3.05$)$ & & \\
\hline & COP_TRA (mm/s) & CON & 7 & $25.19 \pm 5.00$ & $24.23 \pm 5.31$ & -0.96 (-4.08 to 2.17$)$ & 0.03 & 0.06 \\
\hline & RMS ACC ML $\mathrm{DO}\left(\mathrm{m} / \mathrm{s}^{2}\right)$ & INT & 8 & $0.19 \pm 0.09$ & $0.18 \pm 0.06$ & $-0.01(-0.07$ to 0.05$)$ & & \\
\hline & & CON & 5 & $0.18 \pm 0.05$ & $0.14 \pm 0.08$ & $-0.04(-0.12$ to 0.04$)$ & 0.21 & 0.28 \\
\hline & & INT & 8 & $0.24 \pm 0.20$ & $0.26 \pm 0.11$ & $0.02(-0.14$ to 0.19$)$ & & \\
\hline & RMS_ACC_AP_DO (m/s²) & CON & 5 & $0.22 \pm 0.07$ & $0.17 \pm 0.05$ & $-0.06(-0.14$ to 0.03$)$ & 0.26 & 0.41 \\
\hline & RMS FOR MI DO (N) & INT & 8 & $8.31 \pm 2.60$ & $8.72 \pm 2.51$ & $0.40(-2.42$ to 3.23$)$ & 021 & 029 \\
\hline & RIVIS_FUR_MIL_UU (N) & $\mathrm{CON}$ & 5 & $7.69 \pm 0.96$ & $6.98 \pm 0.72$ & $-0.71(-1.79$ to 0.38$)$ & 0.21 & 0.29 \\
\hline & & INT & 8 & $4.90 \pm 1.77$ & $4.45 \pm 1.67$ & $-0.45(-2.17$ to 1.26$)$ & & \\
\hline & RMS_FOR_AP_DO (N) & $\mathrm{CON}$ & 6 & $4.60 \pm 1.31$ & $4.17 \pm 2.15$ & $-0.44(-1.44$ to 0.56$)$ & 0.03 & 0.06 \\
\hline & & INT & 8 & $33.54 \pm 10.68$ & $33.57 \pm 12.38$ & $0.02(-7.55$ to 7.60$)$ & & \\
\hline$\times$ & COP_TRA_DO (mm/s) & $\mathrm{CON}$ & 6 & $30.67 \pm 7.01$ & $27.12 \pm 4.79$ & $-3.55(-8.49$ to 1.40$)$ & 0.25 & 0.41 \\
\hline ळ & & INT & 8 & $0.17 \pm 0.04$ & $0.16 \pm 0.05$ & $-0.01(-0.07$ to 0.05$)$ & & \\
\hline & RMS_ACC_ML_NDO $\left(\mathrm{m} / \mathrm{s}^{2}\right)$ & CON & 7 & $0.19 \pm 0.06$ & $0.23 \pm 0.12$ & $0.04(-0.08$ to 0.15$)$ & 0.25 & 0.45 \\
\hline & & INT & 8 & $0.25 \pm 0.09$ & $0.25 \pm 0.10$ & $0.00(-0.07$ to 0.06$)$ & 003 & 006 \\
\hline & RMS_ACC_AP_NDO $\left(\mathrm{m} / \mathrm{s}^{2}\right)$ & CON & 7 & $0.30 \pm 0.14$ & $0.31 \pm 0.25$ & $0.01(-0.22$ to 0.23$)$ & 0.03 & 0.06 \\
\hline & RMS FOR ML NDO (N) & INT & 7 & $8.24 \pm 1.50$ & $8.80 \pm 1.87$ & $0.56(-0.15$ to 1.27$)$ & 037 & \\
\hline & RMS_FOR_ML_NDO (N) & CON & 6 & $7.79 \pm 1.65$ & $7.49 \pm 1.34$ & $-0.30(-2.04$ to 1.44$)$ & 0.31 & 0.68 \\
\hline & & INT & 8 & $4.43 \pm 1.09$ & $4.43 \pm 1.68$ & $0.00(-0.71$ to 0.71$)$ & & \\
\hline & RMS_FOR_AP_NDO (N) & CON & 6 & $4.48 \pm 0.99$ & $3.60 \pm 0.76$ & $-0.87(-2.45$ to 0.70$)$ & 0.40 & 0.78 \\
\hline & & INT & 8 & $33.54 \pm 8.84$ & $34.33 \pm 13.44$ & $0.80(-5.07$ to 6.67$)$ & 0.49 & 0.92 \\
\hline & CUP_IRA_NDU (mm/s) & CON & 6 & $33.28 \pm 7.31$ & $27.92 \pm 5.24$ & $-5.36(-12.10$ to 1.38$)$ & 0.49 & 0.92 \\
\hline
\end{tabular}

INT = intervention group (TRX-OldAge); $\mathrm{CON}=$ control group (elastic band resistance training); $\mathrm{n}=$ sample size; $\mathrm{M}=$ mean; $\mathrm{SD}=$ standard deviation; $\mathrm{Cl}=$ confidence interval; CSX = closed-leg stance; TSX = tandem stance; SSX = single-leg stance; RMS = root mean square; $A C C=$ lumbar spine sensor acceleration; FOR = force plate force; $\mathrm{ML}=$ medio-lateral direction; $\mathrm{AP}=$ anterior-posterior direction; $\mathrm{DO}=$ dominant leg; $\mathrm{NDO}=$ not dominant leg; $\mathrm{COP}=$ centre of pressure; $\mathrm{TRA}=\mathrm{velocity} ;{ }^{*} \mathrm{p}<0.05$ significant difference in comparison to $\mathrm{T} 1$. 
Tahle 4. Changes of closed-leg stance, tandem stance and single-leg stance on Airex Balance Pad between T1 and T2

\begin{tabular}{|c|c|c|c|c|c|c|c|c|}
\hline & Variable & Group & $n$ & $\begin{array}{c}\mathrm{T} 1 \\
\mathrm{M} \pm \mathrm{SD}\end{array}$ & $\begin{array}{c}\mathrm{T} 2 \\
\mathrm{M} \pm \mathrm{SD}\end{array}$ & $\begin{array}{l}\text { Mean change } \\
(95 \% \mathrm{Cl})\end{array}$ & $\begin{array}{l}\text { Effect } \\
\text { size }\end{array}$ & Power \\
\hline \multirow{6}{*}{ 芯 } & \multirow{2}{*}{ RMS_ACC_ML $\left(\mathrm{m} / \mathrm{s}^{2}\right)$} & INT & 11 & $0.14 \pm 0.05$ & $0.12 \pm 0.04$ & $-0.02(-0.07$ to 0.02$)$ & \multirow{2}{*}{0.12} & \multirow{2}{*}{0.19} \\
\hline & & $\mathrm{CON}$ & 11 & $0.16 \pm 0.05$ & $0.15 \pm 0.09$ & $-0.01(-0.05$ to 0.04$)$ & & \\
\hline & \multirow{2}{*}{ RMS_ACC_AP $\left(\mathrm{m} / \mathrm{s}^{2}\right)$} & INT & 11 & $0.13 \pm 0.03$ & $0.16 \pm 0.05$ & $0.02(-0.01$ to 0.05$)$ & \multirow{2}{*}{0.03} & \multirow{2}{*}{0.06} \\
\hline & & CON & 11 & $0.14 \pm 0.04$ & $0.15 \pm 0.05$ & $0.01(-0.02$ to 0.04$)$ & & \\
\hline & \multirow{2}{*}{ RMS_FOR_ML (N) } & INT & 11 & $6.11 \pm 1.14$ & $6.40 \pm 1.38$ & $0.30(-0.10$ to 0.69$)$ & \multirow{2}{*}{0.17} & \multirow{2}{*}{0.31} \\
\hline & & CON & 9 & $6.48 \pm 1.76$ & $6.59 \pm 1.91$ & $0.10(-0.33$ to 0.54$)$ & & \\
\hline & \multirow{2}{*}{ RMS_FOR_AP (N) } & INT & 10 & $3.69 \pm 1.15$ & $3.65 \pm 1.34$ & $-0.04(-0.55$ to 0.47$)$ & \multirow{2}{*}{0.04} & \multirow{2}{*}{0.07} \\
\hline & & CON & 10 & $3.86 \pm 1.37$ & $3.90 \pm 1.70$ & $0.04(-0.83$ to 0.91$)$ & & \\
\hline & \multirow{2}{*}{ COP_TRA (mm/s) } & INT & 11 & $21.9 \pm 5.79$ & $22.4 \pm 7.09$ & $0.50(-2.80$ to 3.80$)$ & \multirow{2}{*}{0.14} & \multirow{2}{*}{0.22} \\
\hline & & CON & 10 & $23.3 \pm 6.46$ & $22.7 \pm 6.46$ & $-0.60(-3.40$ to 2.20$)$ & & \\
\hline & \multirow{2}{*}{ RMS_ACC_ML (m/s²) } & INT & 5 & $0.25 \pm 0.06$ & $0.19 \pm 0.03$ & $-0.06(-0.14$ to 0.02$)$ & \multirow{2}{*}{0.13} & \multirow{2}{*}{0.10} \\
\hline & & CON & 4 & $0.30 \pm 0.15$ & $0.27 \pm 0.12$ & $-0.02(-0.40$ to 0.36$)$ & & \\
\hline \multirow{8}{*}{ ळ } & \multirow{2}{*}{ RMS_ACC_AP $\left(\mathrm{m} / \mathrm{s}^{2}\right)$} & INT & 5 & $0.51 \pm 0.21$ & $0.40 \pm 0.14$ & $-0.11(-0.21$ to 0.01$)$ & \multirow{2}{*}{0.88} & \multirow{2}{*}{0.99} \\
\hline & & CON & 4 & $0.43 \pm 0.13$ & $0.56 \pm 0.17$ & $0.13(-0.20$ to 0.46$)$ & & \\
\hline & \multirow{2}{*}{ RMS_FOR_ML (N) } & INT & 4 & $10.38 \pm 3.62$ & $9.78 \pm 3.27$ & $-0.60(-2.02$ to 0.82$)$ & & 33 \\
\hline & & CON & 4 & $9.10 \pm 3.45$ & $9.85 \pm 1.42$ & $0.75(-4.62$ to 6.11$)$ & 0.32 & 0.33 \\
\hline & RMS FOR AP (N) & INT & 5 & $6.81 \pm 2.79$ & $4.81 \pm 1.54$ & $-2.00(-3.89$ to -0.10$)$ & 055 & 081 \\
\hline & RIMS_FUR_AP (IN) & CON & 4 & $5.01 \pm 2.78$ & $6.06 \pm 2.68$ & $1.05(-6.00$ to 8.09$)$ & 0.55 & 0.81 \\
\hline & COP TRA $(\mathrm{mm} / \mathrm{s})$ & INT & 4 & $37.70 \pm 9.34$ & $37.00 \pm 9.65$ & $-0.70(-5.30$ to 3.80$)$ & 068 & 089 \\
\hline & CUP_IRA(mIm/s) & CON & 4 & $38.30 \pm 5.24$ & $46.20 \pm 8.61$ & $7.90(-8.00$ to 23.70$)$ & 0.00 & 0.09 \\
\hline & RMS ACC MI D $\left(\mathrm{m} / \mathrm{s}^{2}\right)$ & INT & 7 & $0.31 \pm 0.11$ & $0.26 \pm 0.12$ & $-0.05(-0.18$ to 0.08$)$ & 029 & 0.48 \\
\hline & RIVS_ACC_ML_DU $\left(\mathrm{m} / \mathrm{s}^{2}\right)$ & CON & 6 & $0.36 \pm 0.18$ & $0.49 \pm 0.37$ & $0.13(-0.12$ to 0.38$)$ & 0.29 & 0.48 \\
\hline & RMS ACC AP RO $\left(\mathrm{m} / \mathrm{c}^{2}\right)$ & INT & 7 & $0.56 \pm 0.17$ & $0.53 \pm 0.29$ & $-0.02(-0.26$ to 0.22$)$ & 003 & 005 \\
\hline & RIVIS_ACL_AP_UU $\left(\mathrm{m} / \mathrm{s}^{2}\right)$ & CON & 6 & $0.61 \pm 0.26$ & $0.60 \pm 0.23$ & $-0.01(-0.21$ to 0.19$)$ & 0.03 & 0.05 \\
\hline & RMS EOR MI DO (N) & INT & 7 & $14.31 \pm 5.08$ & $15.80 \pm 8.86$ & $1.49(-5.02$ to 8.00$)$ & 031 & 053 \\
\hline & RIVIS_FUR_ML_DO (N) & CON & 6 & $15.29 \pm 6.59$ & $12.88 \pm 2.99$ & $-2.41(-9.23$ to 4.42$)$ & 0.31 & 0.53 \\
\hline & RMS EOR AP DO (N) & INT & 6 & $7.31 \pm 2.77$ & $7.36 \pm 3.70$ & $0.05(-3.29$ to 3.40$)$ & 003 & 005 \\
\hline & RIVIS_rUR_AT_UU (IV) & $\mathrm{CON}$ & 6 & $7.70 \pm 4.80$ & $7.95 \pm 4.95$ & $0.25(-3.63$ to 4.14$)$ & 0.00 & 0.05 \\
\hline & COP TRA $\mathrm{DO} / \mathrm{mm} / \mathrm{s})$ & INT & 6 & $46.36 \pm 14.18$ & $46.28 \pm 11.65$ & $-0.09(-6.17$ to 5.99$)$ & 024 & 0.26 \\
\hline 昏 & COP_IRA_UU (mm/s) & $\mathrm{CON}$ & 6 & $43.38 \pm 10.56$ & $47.64 \pm 9.89$ & $4.25(-9.01$ to 17.51$)$ & 0.24 & 0.36 \\
\hline ळ & RMS ACC MI $\left.\mathrm{NDO} / \mathrm{m} / \mathrm{c}^{2}\right)$ & INT & 7 & $0.30 \pm 0.16$ & $0.34 \pm 0.14$ & $0.04(-0.06$ to 0.13$)$ & 013 & 013 \\
\hline & RIVIS_ACL_IVL_NUU $\left(\mathrm{m} / \mathrm{s}^{2}\right)$ & CON & 5 & $0.45 \pm 0.20$ & $0.41 \pm 0.18$ & $-0.04(-0.30$ to 0.22$)$ & 0.13 & 0.13 \\
\hline & RMS ACC AP NDO $\left(\mathrm{m} / \mathrm{s}^{2}\right)$ & INT & 7 & $0.57 \pm 0.25$ & $0.63 \pm 0.20$ & $0.06(-0.09$ to 0.21$)$ & 008 & 008 \\
\hline & & CON & 5 & $0.55 \pm 0.15$ & $0.57 \pm 0.23$ & $0.02(-0.39$ to 0.43$)$ & & \\
\hline & RMS FOR MI NDO (N) & INT & 8 & $15.12 \pm 4.77$ & $17.78 \pm 7.03$ & $2.67(-1.44$ to 6.77$)$ & 014 & 015 \\
\hline & RIVIS_FUR_IVIL_NUU (IV) & CON & 5 & $13.41 \pm 3.53$ & $14.64 \pm 7.58$ & 1.23 (-6.98 to 9.43$)$ & 0.14 & 0.15 \\
\hline & RMS FOR AP NDO (N) & INT & 7 & $8.17 \pm 3.55$ & $7.87 \pm 4.05$ & $-0.30(-2.77$ to 2.16$)$ & 130 & 100 \\
\hline & RIVS_FUR_AP_NUU (N) & CON & 5 & $7.94 \pm 2.33$ & $6.93 \pm 1.20$ & $-1.01(-5.16$ to 3.14$)$ & 1.30 & 1.00 \\
\hline & SOP TRA NDO $(\mathrm{mm} / \mathrm{s})$ & INT & 8 & $53.17 \pm 22.33$ & $52.97 \pm 17.30$ & $-0.20(-6.71$ to 6.32$)$ & 016 & 015 \\
\hline & CUP_IRA_NDU (mm/s) & CON & 3 & $35.85 \pm 2.45$ & $37.85 \pm 2.94$ & 2.00 (0.42 to 3.58$)$ & 0.16 & 0.15 \\
\hline
\end{tabular}

INT = intervention group (TRX-OldAge); $\mathrm{CON}=$ control group (elastic band resistance training); $\mathrm{n}=$ sample size; $\mathrm{M}=$ mean; $\mathrm{SD}=$ standard deviation; $\mathrm{Cl}=\mathrm{confidence}$ interval $\mathrm{CSA}=$ closed-leg stance on Airex Balance Pad; TSA = tandem stance on Airex Balance Pad; SSA = single-leg stance on Airex Balance Pad; RMS = root mean square; $\mathrm{ACC}=$ lumbar spine sensor acceleration; $F O R=$ force plate force; $\mathrm{ML}=$ medio-lateral direction; $\mathrm{AP}=$ anterior-posterior direction; $\mathrm{DO}=$ dominant leg; $\mathrm{NDO}=$ not dominant leg; $\mathrm{COP}=$ centre of pressure; TRA = velocity. 


\section{Discussion}

Functional mobility, measured with the MSOT walking with normal (habitual) gait speed, improved significantly by about $5 \%$ in the TRX-OldAge training group. Despite different measurement methods (MSOT and TUG), this result is consistent with previous studies, which documented functional mobility improvements of $5 \%$ to $26 \%$ for older adults (Lee, Lee, 2014; Schroeder et al., 2014).

For upper-body strength, our results are in line with reports of previous studies that could not prove significant group-by-time interactions between sling exercise training and another exercise programme (Dannelly et al., 2011; Prokopy et al., 2008). On the other hand, Bae et al. (2014) demonstrated significant leg strength improvements of $77 \%$ after six weeks of sling training. The main difference between Bae et al. (2014) and our study is that they measured muscle strength isometrically and in older patients with total knee replacement. For younger adults, sling training induced leg strength improvements ranging from 13\% to 27\% (Dannelly et al., 2011; Maté-Muñoz et al., 2014).

However, the significant increase of $9 \%$ in chest press strength in the TRX-OldAge training group is comparable with previous findings in younger adults. These studies showed $4 \%$ to $11 \%$ improvements in chest press strength (Dannelly et al., 2011, Maté-Muñoz et al., 2014, Prokopy et al., 2008).

The results for balance ability showed no significant differences between the two different training groups. To our knowledge, only one sling training study with older adults examined balance ability. After four weeks of training, older chronic hemiplegic patients changed balance significantly by about one point on the Berg Balance Scale (Lee, Lee, 2014). However, the improvements by Lee, Lee (2014) cannot be compared with the quantitative measurements of centre of pressure in the study presented here. In younger participants, Kim et al. (2013) showed a significant sway speed reduction of $23 \%$. Beyond that, after eight weeks of sling training, COP sway length for normal stance significantly decreased by about 30\% (Park, Hwangbo, 2014). In a study by Prokopy et al. (2008), a 12-week sling training induced single-leg stance performance enhancements of $57 \%$ and $65 \%$ for COP sway area. To our knowledge, no sling training study examined tandem stance as a balance ability measure.

Based on the mostly not significant results, some limitations in respect of sample size, measures and intervention should be mentioned. As normal for a first pilot study, the sample size was too small, as power and effect size calculations have shown. Nevertheless, these values can be used for a priori sample size calculations for future studies.

Furthermore, a core stability measurement method should be integrated in the assessment battery, because there is only a small correlation between core stability and balance ability (Granacher, Gollhofer, Hortobágyi, Kressig, Muehlbauer, 2013). However, Lee, Lee (2014) reported increased core muscle activations subsequent to their sling training intervention. Due to the instable design of the implemented TRX-OldAge exercises, it could be assumed that participants of TRX-OldAge improve their core stability, but not their balance ability. Thus, sling training alone would not be sufficient to enhance the complex balance ability of healthy older adults.

To achieve leg strength and balance improvements, the difficulty and load intensity of the TRX-OldAge exercises should be modified or increased to focus more on balance or lower-body strength. One example could be lunges with the forward foot on a board between the foot cradles, as conducted by Schroeder et al. (2012). The only study that reported balance improvements for older adults conducted bridging exercises (prone, supine and lateral) (Lee, Lee, 2014). Therefore, more exercises of this kind should be integrated in TRX-OldAge to enhance core stability and perhaps balance. 
In conclusion, the new TRX-OldAge training programme can be used as a motivating alternative to improve functional mobility and upper-body strength in healthy older adults. In its current description, TRX-OldAge is probably more effectively applicable for more frail and old persons with first mobility limitations. For a further improvement of its effectiveness, TRX-OldAge could be modified to provide higher challenges for fit, healthy older adults, as in the sample of this study.

Based on the present results, it can be concluded that both strength training programmes - TRX-OldAge and an elastic band resistance training - induced similar effects on functional mobility, strength and balance ability in healthy older adults after 12 weeks of training.

\section{Acknowledlyements}

Funding sources: Institute of Movement and Sport Gerontology, German Sport University Cologne; Toyota Germany $\mathrm{GmbH}$, Cologne, Germany (as a result of the second author being rewarded in Toyota's scientific competition). The funding sources played no role in any aspects of this study. We would like to thank Transatlantic Fitness Anywhere, Munich, Germany for providing us with a TRX S Frame and the University Sport Bonn (Peter Preuss) for lending us four TRX Suspension Trainer for the duration of the study. We would also like to express our gratitude to all the participants who gave up their time to take part in the study and the students who helped in terms of data acquisition and supervision of the training sessions. 
Appendix I. Non-significant results of statistical analysis of balance ability without the Airex Balance Pad

\begin{tabular}{|c|c|c|c|c|c|}
\hline \multicolumn{2}{|c|}{ Standing position } & $\begin{array}{c}X^{2} \text {-value/ } \\
\text { F-value }\end{array}$ & \multirow[t]{2}{*}{$d f$} & \multirow{2}{*}{$\begin{array}{c}p \\
0.286\end{array}$} & \multirow{2}{*}{$\begin{array}{c}\mathrm{w} / \\
\eta_{\mathrm{par}}^{2} \\
0.273\end{array}$} \\
\hline \multirow{9}{*}{$\operatorname{cs} x$} & \multirow{3}{*}{ RMS_ACC_ML } & 1.636 & & & \\
\hline & & 2.183 & \multirow[t]{2}{*}{1} & 0.140 & 0.315 \\
\hline & & 0.312 & & 0.577 & 0.119 \\
\hline & \multirow{3}{*}{ RMS_FOR_ML } & 1.169 & \multirow{3}{*}{1,19} & 0.293 & 0.058 \\
\hline & & 0.830 & & 0.374 & 0.020 \\
\hline & & 0.719 & & 0.407 & 0.036 \\
\hline & \multirow{3}{*}{ COP_TRA } & 2.100 & \multirow{3}{*}{1,19} & 0.164 & 0.100 \\
\hline & & 0.632 & & 0.436 & 0.032 \\
\hline & & 0.915 & & 0.351 & 0.046 \\
\hline \multirow{12}{*}{ TSX } & \multirow{3}{*}{ RMS_ACC_ML } & 0.135 & \multirow{3}{*}{1,13} & 0.719 & 0.010 \\
\hline & & 0.875 & & 0.367 & 0.063 \\
\hline & & 0.030 & & 0.864 & 0.002 \\
\hline & \multirow{3}{*}{ RMS_FOR_ML } & 0.006 & \multirow{3}{*}{1,13} & 0.939 & $<0.001$ \\
\hline & & 1.139 & & 0.305 & 0.081 \\
\hline & & 0.029 & & 0.868 & 0.002 \\
\hline & \multirow{3}{*}{ RMS_ACC_AP } & 0.173 & \multirow{3}{*}{1,13} & 0.685 & 0.013 \\
\hline & & 0.803 & & 0.386 & 0.058 \\
\hline & & 0.010 & & 0.921 & 0.001 \\
\hline & \multirow{3}{*}{ COP_TRA } & 0.009 & \multirow{3}{*}{1,13} & 0.924 & 0.001 \\
\hline & & 0.902 & & 0.360 & 0.065 \\
\hline & & 0.301 & & 0.593 & 0.023 \\
\hline & & 0.479 & & 0.503 & 0.042 \\
\hline & RMS_ACC_ML_DO & 1.610 & 1,11 & 0.231 & 0.128 \\
\hline & & 0.371 & & 0.555 & 0.033 \\
\hline & & 0.850 & & 0.373 & 0.061 \\
\hline & RMS_ACC_ML_NDO & 0.226 & 1,13 & 0.642 & 0.017 \\
\hline & & 3.140 & & 0.100 & 0.195 \\
\hline & & 0.502 & & 0.493 & 0.044 \\
\hline & RMS_FOR_ML_DO & 0.037 & 1,11 & 0.851 & 0.003 \\
\hline & & 1.690 & & 0.220 & 0.133 \\
\hline & & 1.520 & & 0.243 & 0.121 \\
\hline & RMS_FOR_ML_NDO & 0.135 & 1,11 & 0.720 & 0.012 \\
\hline & & 1.134 & & 0.310 & 0.093 \\
\hline & & 0.756 & & 0.403 & 0.064 \\
\hline & RMS_ACC_AP_DO & 0.155 & 1,11 & 0.702 & 0.014 \\
\hline $\operatorname{ssx}$ & & 0.936 & & 0.354 & 0.078 \\
\hline SOर & & 0.010 & & 0.922 & 0.001 \\
\hline & RMS_ACC_AP_NDO & 0.001 & 1,13 & 0.978 & $<0.001$ \\
\hline & & 0.744 & & 0.404 & 0.054 \\
\hline & & $<0.001$ & & 0.987 & $<0.001$ \\
\hline & RMS_FOR_AP_DO & 0.962 & 1,12 & 0.346 & 0.074 \\
\hline & & 0.120 & & 0.735 & 0.010 \\
\hline & & 1.905 & & 0.193 & 0.137 \\
\hline & RMS_FOR_AP_NDO & 1.925 & 1,12 & 0.191 & 0.138 \\
\hline & & 0.450 & & 0.515 & 0.036 \\
\hline & & 0.764 & & 0.399 & 0.060 \\
\hline & COP_TRA_DO & 0.746 & 1,12 & 0.405 & 0.059 \\
\hline & & 0.945 & & 0.350 & 0.073 \\
\hline & & 2.831 & & 0.118 & 0.191 \\
\hline & COP_TRA_NDO & 1.553 & 1,12 & 0.237 & 0.115 \\
\hline & & 0.471 & & 0.506 & 0.038 \\
\hline
\end{tabular}

Column $X^{2}$-value/F-value: first value = group-by-time interaction or Friedman; second value = main time effect or Kruskal-Wallis T1; third value = group effect or Kurskal-Wallis T2 CSX = closed-leg stance; TSX = tandem stance; SSX = single-leg stance; RMS = root mean square; $A C C=$ lumbar spine sensor acceleration; FOR = force plate force; $\mathrm{ML}=$ medio-lateral direction; $\mathrm{AP}=$ anterior-posterior direction; $\mathrm{DO}=$ dominant leg; $\mathrm{NDO}=$ not dominant leg; $\mathrm{COP}=$ centre of pressure; $\mathrm{TRA}=\mathrm{velocity} ; \mathrm{df}=\mathrm{degrees}$ of freedom; $p=$ statistical significance; $w / \eta^{2}$ par $=$ effect size. 
Appendix II. Non-significant results of statistical analysis of balance ability on the Airex Balance Pad

\begin{tabular}{|c|c|c|c|c|c|}
\hline & Standing position & $\begin{array}{l}X^{2} \text {-valuel } \\
\text { F-value }\end{array}$ & $d f$ & p & $\begin{array}{c}\mathrm{wl} \\
\eta_{\text {par }}^{2}\end{array}$ \\
\hline \multirow{15}{*}{ CSA } & \multirow{3}{*}{ RMS_ACC_ML } & 0.291 & \multirow{3}{*}{1,20} & 0.595 & 0.014 \\
\hline & & 0.764 & & 0.392 & 0.037 \\
\hline & & 1.265 & & 0.274 & 0.059 \\
\hline & \multirow{3}{*}{ RMS_FOR_ML } & 0.537 & \multirow{3}{*}{1,18} & 0.473 & 0.029 \\
\hline & & 2.363 & & 0.142 & 0.116 \\
\hline & & 0.169 & & 0.685 & 0.009 \\
\hline & \multirow{3}{*}{ RMS_ACC_AP } & 0.018 & \multirow{3}{*}{1,20} & 0.894 & 0.001 \\
\hline & & 2.454 & & 0.133 & 0.109 \\
\hline & & 0.500 & & 0.488 & 0.488 \\
\hline & \multirow{3}{*}{ RMS_FOR_AP } & 0.032 & \multirow{3}{*}{1,18} & 0.860 & 0.002 \\
\hline & & $<0.001$ & & 0.998 & $<0.001$ \\
\hline & & 0.138 & & 0.714 & 0.008 \\
\hline & \multirow{3}{*}{ COP_TRA } & 0.340 & \multirow{3}{*}{1,19} & 0.567 & 0.018 \\
\hline & & 0.001 & & 0.982 & $<0.001$ \\
\hline & & 0.107 & & 0.747 & 0.006 \\
\hline \multirow{12}{*}{ TSA } & \multirow{3}{*}{ RMS_FOR_ML } & 0.597 & \multirow{3}{*}{1,9} & 0.469 & 0.091 \\
\hline & & 0.007 & & 0.935 & 0.001 \\
\hline & & 0.092 & & 0.772 & 0.015 \\
\hline & \multirow{3}{*}{ RMS_ACC_AP } & 5.459 & \multirow{3}{*}{1,7} & 0.052 & 0.438 \\
\hline & & 0.071 & & 0.797 & 0.010 \\
\hline & & 0.180 & & 0.684 & 0.025 \\
\hline & \multirow{3}{*}{ RMS_FOR_AP } & 2.114 & & 0.189 & 0.232 \\
\hline & & 0.206 & 1,7 & 0.664 & 0.029 \\
\hline & & 0.045 & & 0.838 & 0.006 \\
\hline & & 2.753 & & 0.148 & 0.314 \\
\hline & COP_TRA & 1.903 & 1,6 & 0.217 & 0.241 \\
\hline & & 0.850 & & 0.392 & 0.124 \\
\hline & & 0.077 & & $<0.999$ & 0.077 \\
\hline & RMS_ACC_ML_DO & 0.082 & 1 & 0.775 & 0.079 \\
\hline & & 1.306 & & 0.253 & 0.317 \\
\hline & & 0.676 & & 0.430 & 0.630 \\
\hline & RMS_ACC_ML_NDO & $<0.001$ & 10 & 0.993 & $<0.001$ \\
\hline & & 1.440 & & 0.258 & 0.126 \\
\hline & & 1.058 & & 0.326 & 0.088 \\
\hline & RMS_FOR_ML_DO & 0.059 & 1,11 & 0.813 & 0.005 \\
\hline & & 0.107 & & 0.750 & 0.010 \\
\hline & & 0.204 & & 0.661 & 0.018 \\
\hline & RMS_FOR_ML_NDO & 1.492 & 1,11 & 0.247 & 0.119 \\
\hline & & 0.646 & & 0.439 & 0.055 \\
\hline & & 0.012 & & 0.913 & 0.001 \\
\hline & RMS_ACC_AP_DO & 0.066 & 1,11 & 0.803 & 0.006 \\
\hline SSA & & 0.251 & & 0.626 & 0.022 \\
\hline SSA & & 0.070 & & 0.796 & 0.007 \\
\hline & RMS_ACC_AP_NDO & 0.326 & 1,10 & 0.580 & 0.032 \\
\hline & & 0.175 & & 0.685 & 0.017 \\
\hline & & 0.010 & & 0.921 & 0.001 \\
\hline & RMS_FOR_AP_DO & 0.023 & 1,10 & 0.881 & 0.002 \\
\hline & & 0.051 & & 0.827 & 0.005 \\
\hline & & 0.168 & & 0.691 & 0.017 \\
\hline & RMS_FOR_AP_NDO & 0.576 & 1,10 & 0.465 & 0.054 \\
\hline & & 0.121 & & 0.735 & 0.012 \\
\hline & & 0.586 & & 0.462 & 0.055 \\
\hline & COP_TRA_DO & 0.538 & 1,10 & 0.480 & 0.051 \\
\hline & & 0.017 & & 0.897 & 0.002 \\
\hline & & & & 0.648 & 0.024 \\
\hline & COP_TRA_NDO & 0.150 & 1,9 & 0.707 & 0.016 \\
\hline & & 1.913 & & 0.200 & 0.175 \\
\hline
\end{tabular}

Column $X^{2}$-value/F-value: first value = group-by-time interaction or Friedman; second value = main time effect or Kruskal-Wallis T1; third value = group effect or Kurskal-Wallis T2 INT = intervention group (TRX-OldAge); $\mathrm{CON}=$ control group (elastic band resistance training); $\mathrm{n}=$ sample size; $\mathrm{M}=$ mean; $\mathrm{SD}=$ standard deviation; $\mathrm{Cl}=$ confidence interval; $\mathrm{CSA}=$ closed-leg stance on Airex Balance Pad; TSA = tandem stance on Airex Balance Pad; SSA = single-leg stance on Airex Balance Pad; RMS = root mean square; $A C C=$ lumbar spine sensor acceleration; $F O R=$ force plate force; $M L=$ medio-lateral direction; $A P=$ anterior-posterior direction; $D O=$ dominant leg; $N D O=$ not dominant leg; $\mathrm{COP}=$ centre of pressure; TRA = velocity; $d f=$ degrees of freedom; $p=$ statistical significance; $w / \eta^{2}$ par $=$ effect size. 


\section{References}

Ainsworth, B.E., Haskell, W.L., Whitt, M.C., Irwin, M.L., Swartz, A.M., Strath, S.J., Leon, A.S. (2000). Compendium of physical activities: an update of activity codes and MET intensities. Medicine \& Science in Sports \& Exercise, 32 (9 Suppl), 498-504. DOI: 10.1097/00005768-200009001-00009.

Bae, C.H., Jung, Y.W., Lee, D.W., Cho, S.H. (2014). The effect of sling exercise on muscular strength and range of motion in female patients who received total knee replacement. Journal of the Korea Academia-Industrial cooperation Society, 15 (7), 4395-4403. DOI: 10.5762/KAIS.2014.15.7.4395

Barnett, A., Smith, B., Lord, S.R., Williams, M., Baumand, A. (2003). Community-based group exercise improves balance and reduces falls in at-risk older people: a randomised controlled trial. Age and Ageing, 32 (4), 407-414. DOI: 10.1093/ageing/32.4.407.

Choi, Y.R., Kim, J.W., Hwang, B.J. (2011). The effect of lumbar muscle strengthening exercise types on balance and walking ability of elderly. Journal of International Academy of Physical Therapy Research, 2 (2), 267-343. DOI: 10.5854/JIAPTR.2011.2.2.329.

Clemson, L., Fiatarone Singh, M.A., Bundy, A., Cumming, R.G., Manollaras, K., O'Loughlin, P., Black, D. (2012). Integration of balance and strength training into daily life activity to reduce rate of falls in older people (the LiFE study): randomised parallel trial. BMJ (Clinical research ed.), 345, e4547. DOI: 10.1136/bmj.e4547.

Dannelly, B.D., Otey, S.C., Croy, T., Harrison, B., Rynders, C.A., Hertel, J.N., Weltman, A. (2011). The effectiveness of traditional and sling exercise strength training in women. The Journal of Strength and Conditioning Research, 25 (2), 464-471. DOI: 10.1519/ JSC.0b013e318202e473.

Fahlman, M.M., McNevin, N., Boardley, D., Morgan, A., Topp, R. (2011). Effects of resistance training on functional ability in elderly individuals. American Journal of Health Promotion, 25 (4), 237-243. DOI: 10.4278/ajhp.081125-QUAN-292.

Faul, F., Erdfelder, E., Lang, A.G., Buchner, A. (2007). G*Power 3: a flexible statistical power analysis program for the social, behavioral and biomedical sciences. Behavior Research Methods, 39 (2), 175-191. DOI: 10.3758/BF03193146.

Gaedtke, A., Morat, T. (2015). TRX suspension training: A new functional training approach for older adults - development, training control and feasibility. International Journal of Exercise Science, 8 (3), 224-233.

Gießing, J. (2003). Trainingsplanung und -steuerung beim Muskelaufbautraining: Das Konzept vom individuellen hypothetischen Maximalgewicht (h1RM) als methodische Alternative. Leistungssport, 33 (4), 26-31.

Granacher, U., Gollhofer, A., Hortobágyi, T., Kressig, R.W., Muehlbauer, T. (2013). The importance of trunk muscle strength for balance, functional performance, and fall prevention in seniors: a systematic review. Sports Medicine, 43 (7), 627-641. DOI: 10.1007/ s40279-013-0041-1.

Henwood, T.R., Taaffe, D.R. (2006). Short-term resistance training and the older adult: the effect of varied programmes for the enhancement of muscle strength and functional performance. Clinical Physiology and Functional Imaging, 26 (5), 305-313. DOI: 10.1111/j.1475-097X.2006.00695.x.

Huy, C., Schneider, S. (2008). Instrument für die Erfassung der physischen Aktivität bei Personen im mittleren und höheren Erwachsenenalter. Zeitschrift für Gerontologie und Geriatrie, 41 (3), 208-216. DOI: 10.1007/s00391-007-0474-y.

Irez, G.B., Ozdemir, R.A., Evin, R., Irez, S.G., Korkusuz, F. (2011). Integrating pilates exercise into an exercise program for 65+ year-old women to reduce falls. Journal of Sports Science \& Medicine, 10 (1), 105-111.

Kaesler, D.S., Mellifont, R., Kelly, P.S., Taaffe, D.R. (2007). A novel balance exercise program for postural stability in older adults: A pilot study. Journal of Bodywork and Movement Therapies, 11, 37-43. DOI:10.1016/j.jbmt.2006.05.003.

Kim, J.H., Kim, Y.E., Bae, S.H., Kim, K.Y. (2013). The effect of the neurac sling exercise on postural balance adjustment and muscular response patterns in chronic low back pain patients. Journal of Physical Therapy Science, 25 (8), 1015-1019. DOI: 10.1589/ jpts.25.1015.

Krebs, D.E., Scarborough, D.M., McGibbon, C.A. (2007). Functional vs. strength training in disabled elderly outpatients. American Journal of Physical Medicine \& Rehabilitation, 86 (2), 93-103. DOI: 10.1097/PHM.0b013e31802ede64.

Lee, J.S., Lee, H.G. (2014). Effects of sling exercise therapy on trunk muscle activation and balance in chronic hemiplegic patients. Journal of Physical Therapy Science, 26 (5), 655-659. DOI: 10.1589/jpts.26.655.

Lohne-Seiler, H., Torstveit, M.K., Anderssen, S.A. (2013). Traditional versus functional strength training: effects on muscle strength and power in the elderly. Journal of Aging and Physical Activity, 21 (1), 51-70. 
Maté-Muñoz, J.L., Monroy, A.J. A., Jodra Jiménez, P., Garnacho-Castaño, M.V. (2014). Effects of instability versus traditional resistance training on strength, power and velocity in untrained men. Journal of Sports Science \& Medicine, 13 (3), 460-468.

Morat, T., Kroeger, D., Mechling, H. (2013). The Multisurface Obstacle Test for older adults (MSOT): development and reliability of a novel test for older adults. European Review of Aging and Physical Activity, 10 (2), 117-125. DOI: 10.1007/s11556-013-0121-0.

O'Shea, S.D., Taylor, N.F., Paratz, J.D. (2007). A predominantly home-based progressive resistance exercise program increases knee extensor strength in the short-term in people with chronic obstructive pulmonary disease: a randomised controlled trial. The Australian Journal of Physiotherapy, 53 (4), 229-237. DOI: 10.1016/S0004-9514(07)70003-X.

Park, J.H., Hwangbo, G. (2014). The effect of trunk stabilization exercises using a sling on the balance of patients with hemiplegia. Journal of Physical Therapy Science, 26(2), 219-221. DOI:10.1589/jpts.26.219.

Prokopy, M.P., Ingersoll, C.D., Nordenschild, E., Katch, F.I., Glenn, A.G., Weltman, A. (2008). Closed-kinetic chain upper-body training improves throwing performance of NCAA division I softball players. The Journal of Strength and Conditioning Research, 22 (6), 1790-1798. DOI: 10.1519/JSC.0b013e318185f637.

Ribeiro, F., Teixeira, F., Brochado, G., Oliveira, J. (2009). Impact of low cost strength training of dorsi- and plantar flexors on balance and functional mobility in institutionalized elderly people. Geriatrics \& Gerontology International, 9 (1), 75-80. DOI: 10.1111/j.1447-0594.2008.00500.x.

Robertson, R.J., Goss, F.L., Rutkowski, J., Lenz, B., Dixon, C., Timmer, J., Andreacci, J. (2003). Concurrent validation of the OMNI perceived exertion scale for resistance exercise. Medicine and Science in Sports and Exercise, 35 (2), 333-341. DOI: 10.1249/01. MSS.0000048831.15016.2A.

Schroeder, G., Knauerhase, A., Kundt, G., Schober, H.C. (2012). Effects of physical therapy on quality of life in osteoporosis patients a randomized clinical trial. Health and Quality of Life Outcomes, 10 (1), 101. DOI: 10.1186/1477-7525-10-101.

Schroeder, G., Knauerhase, A., Kundt, G., Schober, H.C. (2014). Trunk stabilization with sling training in osteoporosis patients. European Review of Aging and Physical Activity, 11 (1), 61-68. DOI: 10.1007/s11556-013-0128-6.

Sherrington, C., Tiedemann, A., Fairhall, N., Close, J.C.T., Lord S.R. (2011). Exercise to prevent falls in older adults: an updated metaanalysis and best practice recommendations. New South Wales Public Health Bulletin, 22 (4), 78-83. DOI: 10.1071/NB10056.

Solberg, P.A., Kvamme, N.H., Raastad, T., Ommundsen, Y., Tomten, S. E., Halvari, H., Hallén, J. (2013). Effects of different types of exercise on muscle mass, strength, function and well-being in elderly. European Journal of Sport Science, 13 (1), 112-125. DOI: 10.1080/17461391.2011.617391.

Spring, T., Franklin B., .de Jong A. (2010). Muscular fitness and assessment. In: American College of Sports Medicine (ed.), ACSM's Resource Manual for Guidelines for Exercise Testing and Prescription (pp. 332-348). Philadelphia: Wolters Kluwer, Lippincott Williams \& Wilkins.

Stray-Pedersen, J.I., Magnussen, R., Kuffel, E., Seiler, S., Katch, F. (2006). Sling exercise training improves balance, kicking velocity, and torso stabilization strength in elite soccer players. Medicine \& Science in Sports \& Exercise, 38 (5), S243.

Taylor, D., Hale, L., Schluter, P., Waters, D.L., Binns, E.E., McCracken, H., Wolf, S.L. (2012). Effectiveness of tai chi as a communitybased falls prevention intervention: a randomized controlled trial. Journal of the American Geriatrics Society, 60 (5), $841-848$. DOI: 10.1111/j.1532-5415.2012.03928.x.

Tsauo, J.Y., Cheng, P.F., Yang, R.S. (2008). The effects of sensorimotor training on knee proprioception and function for patients with knee osteoarthritis: a preliminary report. Clinical Rehabilitation, 22 (5), 448-457. DOI: 10.1177/0269215507084597.

Vandervoort, A.A. (2002). Aging of the human neuromuscular system. Muscle \& Nerve, 25 (1), 17-25. DOI: 10.1002/mus.1215.

Cite this anticle aS: Gaedtke, A., Morat, T. (2016). Effects of Two 12-week Strengthening Programmes on Functional Mobility, Strength and Balance of Older Adults: Comparison between TRX Suspension Training versus an Elastic Band Resistance Training. Central European Journal of Sport Sciences and Medicine, 13 (1), 49-64. DOI: 10.18276/cej.2016.1-05. 